\title{
Conditioned Place Preference Deficits in Adulthood Following High Fat and High Sugar Diet Intake in Pre- and Periadolescence: A Test of the Specificity Hypothesis
}

\author{
Gregory J. Privitera*, Darryl J. Mayeaux, Rachel A. Schey, Hannah E. Lapp \\ Department of Psychology, Saint Bonaventure University, St. Bonaventure, USA \\ Email: "gprivite@sbu.edu
}

Received October 14, 2013; revised November 5, 2013; accepted November 13, 2013

Copyright (C) 2013 Gregory J. Privitera et al. This is an open access article distributed under the Creative Commons Attribution License, which permits unrestricted use, distribution, and reproduction in any medium, provided the original work is properly cited.

\begin{abstract}
Obesity is linked to poorer cognitive performance, both of which may result from eating high-fat foods during development. In the present study, pre- and periadolescent (postnatal days 21 to 40) male rats were fed high fat (HF), high sugar (HS), or rodent chow (Chow) diets. After conditioning for 16 days with either Cheetos ${ }^{\circledR}$ (high-fat) or Froot Loops ${ }^{\circledR}$ (high-sugar) unconditioned stimuli (US) on one side of a conditioned place preference (CPP) apparatus, rats were tested on postnatal day 61 for a place preference. Chow rats preferred the US-paired side, but HF rats showed no preference. HS rats preferred the side paired with Cheetos ${ }^{\circledR}$ but not with Froot Loops ${ }^{\circledR}$. In spite of these deficits, object recognition, a nonassociative learning task, was not impaired. These results show mixed support for the specificity hypothesis, which predicts that CPP deficits will be nutrient-specific. The results show for the first time that eating a HS diet leads to a nutrient-specific CPP deficit (for HS foods), whereas eating a HF diet leads to a general CPP deficit (for HS and HF foods).
\end{abstract}

Keywords: High Fat Diet; High Sugar Diet; CPP; Cheetos ${ }^{\circledR}$; Froot Loops ${ }^{\circledR}$

\section{Introduction}

Obesity is one of the most serious and fastest growing public health problems worldwide with an estimated $63 \%$ of the adult population in the US being overweight or obese [1], with morbidity and mortality linked to obesity on the rise [2]. One major contributing factor, known as a key factor of interest in the present work, to the rising obesity rates, is the increased intake of high fat, energy-dense foods in the human diet [3,4], which is also associated with cognitive impairments in adolescents and adults [5-7]. High fat diet intake specifically consumed in adolescence can be particularly detrimental to the critical neurodevelopment of brain structures involved in cognitive functioning, such as the hippocampus [8], and the elimination of the expression of learning for food USs, to include evidence using the conditioned place preference (CPP) paradigm [9].

Studies using the CPP paradigm show that rats and mice prefer the approach environmental cues that are associated with consumption of high fat (HF) foods, in-

${ }^{*}$ Corresponding author. cluding open source HF diet pellets [10], fried potatoes [11], corn oil [12], and Cheetos ${ }^{\circledR}[13,14]$; and high sugar (HS) foods such as Froot Loops ${ }^{\circledR}[13,14]$. In the CPP paradigm, the HF or HS food serves as an unconditioned stimulus (US) that is consumed in a distinct place with a presumably neutral set of environmental cues serving as the conditioned stimulus (CS). The CS acquires secondary motivational properties in a condition that elicits an approach response in test, i.e., when allowed to roam freely the subject spends most of its time in the presence of the CS instead of a control place $[15,16]$.

Recent evidence shows that intake of a HF diet consumed only in pre- and periadolescence, results in longlasting deficits on CPP performance that persist into adulthood [9]. Rats consuming a HF diet (60\% kcal fat) during postnatal days (PD) 21 - 40 failed to express a CPP for a place associated with a high fat food (Cheetos $\left.{ }^{\circledR}\right)$. Rats fed a HS or standard lab chow diet in PD 21 40 and rats fed a HF diet in adulthood for 20 days showed no CPP deficits, i.e., subjects in these groups showed a preference for a place associated with a HF food. HF diet intake during PD 21 - 40 is significant as 
much as this is a critical period for maturation and brain development analogous to pre- and periadolescence in humans [17].

One possible explanation for the failure of rats to express CPP following pre- and periadolescent intake of a HF diet is evidence that intake of HF diets specifically during this developmental period can lead to neural impairments [8]. The impairments observed are hippocamapal neurogenesis impairment that specifically disrupts the ability of adult-born neurons to integrate into the hippocampal circuitry - thereby interfering with the ability of a subject to use previously learned information in a novel situation [18,19]. The hippocampus extends neuronal projections that interconnect it with key structures: the amygdala [20,21] and nucleus accumbens [22], which is specifically implicated in CPP performance with HF and HS foods used as a US $[13,14]$.

If a HF diet consumed in pre- and periadolescence can disrupt the connection of hippocampal neurons with key brain regions known to promote CPP performance, then CPP deficits following pre- and periadolescence intake of a HF diet may be observed with any type of food nutrient US, i.e., general CPP deficits should be observed. However, to date, manipulations of HF diet intake in pre- and periadolescence have only shown that subjects fail to prefer a place associated with a HF food reward in adulthood. It is still unclear if these deficits are specific to using HF USs in the CPP chamber, or if these deficits will also occur with other nutrient USs, such as a HS US. Privitera et al. [9] proposed the specificity hypothesis, which states that HF diet-induced CPP deficits will be specific — or will only be observed - when a HF US is used in the CPP chamber. Recent evidence of neuronal impairment seems to contradict this prediction and instead predict that CPP deficits may be general due to permanent degeneration of neurons caused by intake of $\mathrm{HF}$ diet in pre- and periadolescence, i.e., CPP deficits should be observed with any type of nutrient US.

To test the specificity hypothesis, rat subjects were given the diet manipulation in PD 21 - 40 (pre- and periadolescence; [17]) and also given CPP trials, which is an associative learning task. Because it was predicted that some CPP deficits were likely to arise [8,9], we included a priori follow-up test using the nonassociative novel object recognition (NOR) task to determine if subjects, even those who showed a deficit, could at least express basic learning and memory for a nonassociative learning task $[23,24]$.

\section{Materials and Method}

\subsection{Subjects}

Forty-two male Sprague-Dawley rats in four all-male litters (Charles River Laboratories, Kingston, New York) were 15 or 16 days old upon arrival to the lab with their dam. Beginning at 21 days of age and continuing for the remainder of the study, males were housed individually in clear plastic cages $(43 \mathrm{~cm}$ deep $\times 21 \mathrm{~cm}$ wide $\times 20 \mathrm{~cm}$ high). Cages had solid bottoms covered with bedding (Sani-Chips, P.J. Murphy Forest Products, Montville, NJ) and stainless steel wire lids. Access to water and lab chow (Harlan Teklad 2018, Madison, Wisconsin, USA) was continuous, except during PD 21 - 40 as described in the procedures section. Lights were on a 10:14 hour dark:light cycle with lights off at 1130 hours. Temperature (approximately 23C) and humidity (approximately $50 \%$ ) in the housing and testing rooms were controlled. Rats were familiarized with handling procedures prior to conducting experimental procedures.

\subsection{Diet and US Stimuli}

Five different foods were used. During pre- and periadolescence only (PD 21 - 40), rats ate exclusively one of three commercially available rodent diets: lab chow, high fat, or high sugar. During CPP training, rats could eat either high-fat Cheetos ${ }^{\circledR}$ or high-sugar Froot Loops ${ }^{\circledR}$. Nutrient contents of the foods/diets and the phase in which the foods/diets were consumed are given in Table 1. The high-fat and high-sugar diets were matched for $\%$ kcal protein and differed on carbohydrate [CHO] and fat content to match overall kcal. Cheetos ${ }^{\circledR}$ and Froot Loops ${ }^{\circledR}$ were used because these foods are equally rewarding and have been successfully used as HF or HS USs, respectively, in previous CPP studies $[9,13,14]$. In this study, Cheetos $^{\circledR}$ and Froot Loops ${ }^{\circledR}$ could be consumed only during PD 41 - 60.

\subsection{Apparatuses}

CPP apparatus. Each of the two end chambers of the

Table 1. Nutrient content and sources of food.

\begin{tabular}{|c|c|c|c|c|}
\hline \multirow[b]{2}{*}{ Phase in study } & \multirow[b]{2}{*}{ Food } & \multicolumn{3}{|c|}{$\%$ kilocalories } \\
\hline & & Fat & $\mathrm{CHO}$ & Protein \\
\hline \multicolumn{5}{|c|}{ PD 21 - 40: Diet manipulation } \\
\hline & Lab chow $^{\mathrm{a}}$ & 18 & 58 & 24 \\
\hline & High fat ${ }^{b}$ & 60 & 20 & 20 \\
\hline & High sugar $^{\mathrm{c}}$ & 10 & 70 & 20 \\
\hline \multicolumn{5}{|c|}{$\begin{array}{l}\text { PD } 41 \text { - 60: Sensory } \\
\text { Familiarization \& CPP training }\end{array}$} \\
\hline & Cheetos $^{\circledR d}$ & 56 & 38 & 6 \\
\hline & Froot Loops ${ }^{\circledR e}$ & 5 & 91 & 4 \\
\hline
\end{tabular}


CPP apparatus $(26 \mathrm{~cm}$ long $\times 30 \mathrm{~cm}$ wide $\times 32 \mathrm{~cm}$ tall, Model H10-11R-TC, Coulbourn Instruments, Allentown, Pennsylvania, USA) had stainless steel sidewalls and plastic front and back walls. The two end chambers had a metal grid floor and differed by the design on the front and back walls. The walls of one chamber had dark vertical stripes; the second chamber had dark horizontal stripes. No bedding was beneath the floor in either chamber. The proximal sidewalls of the two chambers were connected by a median zone $(13 \mathrm{~cm}$ long $\times 23 \mathrm{~cm}$ wide $\times$ $15.25 \mathrm{~cm}$ tall, Model H10-37R-NSF-09W, Coulbourn Instruments, Allentown, Pennsylvania, USA), which also had clear plastic walls and a metal grid floor. Food cups were placed in the far back corner of the wall furthest from the median zone in each end chamber.

Open field. An open field measuring $59 \mathrm{~cm} \times 59 \mathrm{~cm} \times$ $31.5 \mathrm{~cm}$ high was used for object recognition. The floor and three walls of the plywood apparatus were painted white; the front was removable clear plastic. On the floor in each of the two rear corners, $10 \mathrm{~cm}$ from the side and rear walls, was adhesive fabric to which objects could be secured.

The CPP apparatus and the open field were located in a testing room adjacent to the animal housing room. The testing was dimly lit with a $40 \mathrm{~W}$ desk lamp.

\subsection{Procedure}

A completely randomized design was used to create six groups. Half of the subjects within each of three diet manipulations (PD 21 to 40), were randomly assigned to Cheetos $^{\circledR}$ and half to Froot Loops ${ }^{\circledR}$ (for PD 44 to 60; Table 2).

Diet Manipulation, PD 21 - 40 (Phase 1). Upon being placed into separate cages, subjects consumed either a HF diet, a HS diet, or a standard rodent lab chow diet ad $l i b$ in their home cages for 20 days from PD 21 - 40. This

Table 2. Sample sizes of six groups formed from manipulation of diet and US foods used for CPP training.

\begin{tabular}{|c|c|c|c|}
\hline $\begin{array}{c}\text { PD } 21 \text { to } 40 \\
\text { (Diet manipulation) }\end{array}$ & $\begin{array}{l}\text { PD } 45 \text { to } 60 \text { (US used } \\
\text { in CPP training) }\end{array}$ & Group Name & $\mathrm{n}$ \\
\hline \multicolumn{4}{|l|}{ High fat (HF) } \\
\hline & Cheetos $^{\circledR}$ & HF-Cheetos & 7 \\
\hline & Froot Loops ${ }^{\circledR}$ & HF-Froot Loops & 7 \\
\hline \multicolumn{4}{|l|}{ High sugar (HS) } \\
\hline & Cheetos $^{\circledR}$ & HS-Cheetos & 7 \\
\hline & Froot Loops $^{\mathbb{B}}$ & HS-Froot Loops & 7 \\
\hline \multicolumn{4}{|l|}{ Chow (Chow) } \\
\hline & Cheetos $^{\circledR}$ & Chow-Cheetos & 7 \\
\hline & Froot Loops ${ }^{\circledR}$ & Chow-Froot Loops & 7 \\
\hline
\end{tabular}

developmental period was chosen because it is analogous to preadolescence and periadolescence in humans [17]. Thereafter, all rats consumed a standard lab chow in their home cages. Twice a week from postnatal days 42 to 59 subjects' weights were recorded to the nearest gram $(\mathrm{g})$.

Sensory Familiarization, PD 41 - 44 (Phase 2). In the home cage, both Cheetos ${ }^{\circledR}$ and Froot Loops ${ }^{\circledR}$ were given to standardize food intake histories across all groups, and to reduce neophobic responding to these USs in the CPP chamber, as was observed in a previous study [9]. Rats were given $1 \mathrm{~g}$ of each US food on PD 41, and $2 \mathrm{~g}$ of each US food for the next three days. Lab chow was removed from home cages at least one hour prior to and replaced at least one hour after the procedures described to eliminate the possibility that intake of the US foods was associated with intake of lab chow.

CPP Training, PD 45 - 60 (Phase 3). Subjects were placed in one side of the CPP apparatus for 20 minutes each day for 16 days on an ABBA counterbalancing schedule. Half the rats in each group were given ad lib access to Cheetos $^{\circledR}$ or Froot Loops ${ }^{\circledR}$ in the vertical stripes side on A days and lab chow pellets in the horizontal stripes side on B days; the other half of rats had reverse pairings. Between 4 and $12 \mathrm{~g}$ of the US food or lab chow was placed into the open cup in the chamber. The difference in the weight of the food from before to after each 20-min trial was recorded. The side that rats received a US was counterbalanced within groups, which is an effective procedure for increasing effect sizes for a CPP [15]. On each day, lab chow was removed from home cages at least one hour prior to and replaced at least one hour after each trial.

CPP Testing, PD 61 (Phase 4). Lab chow was removed from home cages at least one hour prior to testing. No food was available in the CPP apparatus during the test. The barrier blocking the median zone between each CPP chamber was removed. Each rat was placed in a neutral position in the median zone and allowed for 20 minutes to move freely between the two chambers (one previously paired with lab chow and one with either Cheetos ${ }^{\circledR}$ or Froot Loops ${ }^{\circledR}$ ) via the median zone.

Time in the CPP chambers was recorded to the nearest $0.1 \mathrm{sec}$ using a laptop computer running The Observer 5.0 (Noldus Information Technology, Sterling, Virginia, USA). A rat was judged to have moved from one chamber of the CPP apparatus to another when his full body, but not necessarily his tail, was in the new chamber. Entry into a chamber was coded by an observer pressing corresponding keys on the laptop computer. After the end of a trial, the program calculated the number of entries into and total duration in each of the two chambers.

Object Recognition (Follow-up Test). This task was modeled after those described elsewhere [25,26]. The object recognition test required four 5-min trials in the 
open field on three consecutive days. First, rats were allowed one trial to investigate the open field without objects present. On the second day, rats received a training trial with two identical objects that were affixed to the adhesive fabric. Six pairs of identical wooden children's toy blocks had similar texture, color, and size, but had distinctive shapes. One hour later, in a follow-up to the training trial, one familiar object, which was the same as the training trial, and one novel object, which they had not yet encountered were affixed to the adhesive fabric. On the third day, in a 24-hour follow-up to the training trial, the familiar object and one more novel object, which they had not yet encountered were affixed to the adhesive fabric. "Familiar" objects for one rat served as "novel" objects for another rat in a counterbalanced fashion across subjects within a group. Moreover, the side (left vs. right) of the novel object was the same for the 1-hour and the 24-hour follow-ups for a single subject but was counterbalanced across subjects within a group. Investigation of an object was defined as when the rat's nose was no more than $0.5 \mathrm{~cm}$ from the object, licking or gnawing the object, or touching the object with the front paws. Sitting on the object was not considered investigation. Investigation was recorded to the nearest 0.1 sec using a laptop computer running The Observer 5.0 (Noldus Information Technology, Sterling, Virginia, USA). An observer pressed keys on the laptop computer that corresponded to investigation of either object. The program calculated total duration of investigation.

After each trial of CPP training, CPP testing, and object recognition, the apparatus and objects were cleaned with a $50 \% \mathrm{ETOH}$ solution to minimize the chance that scents from one rat were a distraction to the next rat tested.

All procedures followed internationally recognized guidelines for ethical conduct in the care and use of animals. The university's Institutional Animal Care and Use Committee approved all procedures.

\subsection{Statistical Analysis}

Differences among groups in body weight were assessed using an analysis of variance (ANOVA) with groups (6 levels) as the between-subjects factor and age (6 levels) as the within-subjects factor.

Intake (g) of Cheetos ${ }^{\circledR}$, Froot Loops ${ }^{\circledR}$, and lab chow during CPP training was converted to kilocalories (kcal) and analyzed using a mixed ANOVA. Groups was the between-subjects factor, and days (8) of training with a particular food was the within-subjects factor.

A CPP was defined as greater time spent in the chamber previously paired with the US food compared to time spent in the chamber previously paired with standard lab chow. Previous studies with 3-chamber CPP systems $[27,28]$ show that time spent in a median zone is similar between groups. This was also true in the present study, so time spent in the median zone was not interpreted. During CPP testing, the expectation was that more time would be spent in the chamber paired with Cheetos ${ }^{\circledR}$ or with Froot Loops ${ }^{\circledR}$ than would be spent in the chamber paired with lab chow. Therefore, the proportion of time spent on the non-preferred side of the CPP chamber was subtracted from the proportion of time spent on the preferred side to yield a difference score. The 95\% confidence interval (CI) was calculated for the differences scores of each group. A preference was identified if the mean difference score was positive and the CI did not envelop zero.

For the CPP test, the number of chamber entrances was assessed with a one-way ANOVA between groups. All ANOVA tests were conducted at a 0.05 level of significance.

Analysis of investigation of objects in the open field during the 1-hr and 24-hr follow-up was similar to that used for CPP testing. Proportion of total investigation time directed toward the familiar object was subtracted from the proportion of total investigation time directed toward the novel object. Ninety five percent CIs were calculated for these difference scores for each diet manipulation group at each of the two follow-up test times. A preference for the novel object was identified if the mean difference score was positive and the CI did not envelop zero.

\section{Results}

Body Weight, Sensory Familiarization and CPP Training (PD 41 to 59). Body weight increased by approximately $80 \%$ from postnatal days 42 to 59 (Table 3; $F(5,195)=$ $1260.69, p<0.001)$. This measure did not, however, differ among the three diet manipulation groups $(F(2,39)=$ $0.42, p=0.66$ ) nor did the change across days vary by group (groups $\mathrm{X}$ days interaction: $F(10,195)=0.58, p=$ 0.83 ). Taken together this pattern suggests that rats in the HF diet manipulation group compensated for the added energy intake per $g$ by reducing overall $g$ of intakes during the diet manipulation.

Food Consumed during CPP Training ( $P D 44$ to 60). Consumption of all types of food in the CPP apparatus increased at least two-fold across the days of training. Across days of pairing standard lab chow with one side of the CPP apparatus (days 2, 3, 6, 7, 10, 11, 14, and 15), kcals consumed doubled (Figure 1: $F(7,273)=6.22, p<$ $0.001)$. Although the diet manipulation groups did not differ from each other $(F(2,39)=0.86, p=0.43)$, the increase in the consumption of lab chow did vary by group (group $\mathrm{X}$ day interaction: $F(14,273)=2.02, p<$ $0.02)$. On Day 11, the HF group consumed more chow than did the Chow group (Tukey's $p<0.05$ ).

Across days of pairing either Cheetos ${ }^{\circledR}$ or Froot Loops ${ }^{\circledR}$ 
Table 3. Mean body weight in grams \pm SEM by group from sensory familiarization through CPP training.

\begin{tabular}{ccccccrc}
\hline & \multicolumn{5}{c}{ Postnatal Day (PD) } \\
\hline Diet Manipulation & 42 & 45 & 49 & 52 & 56 & 59 \\
HF & $204 \pm 10$ & $219 \pm 11$ & $267 \pm 9$ & $291 \pm 10$ & $337 \pm 10$ & $365 \pm 8$ \\
HS & $196 \pm 10$ & $217 \pm 12$ & $266 \pm 12$ & $292 \pm 13$ & $338 \pm 13$ & $365 \pm 10$ \\
Chow & $193 \pm 10$ & $207 \pm 11$ & $255 \pm 10$ & $280 \pm 10$ & $324 \pm 9$ & $349 \pm 9$ \\
\hline
\end{tabular}



Figure 1. Mean intake \pm SEM of lab chow in kcal in CPP training by rats with pre- and periadolescent intake of $\mathrm{HF}$, HS or lab chow diet. HF group was significantly different from Chow group on Day $11(p<0.05)$.

with the other side of the CPP apparatus (Days 1, 4, 5, 8, $9,12,13$, and 16), kcals consumed more than doubled (Figure 2: $F(7,252)=26.63, p<0.001)$. Although the groups did not differ $(F(5,36)=0.49, p=0.78)$, the increase in consumption did vary by group (group $\mathrm{X}$ days interaction: $F(35,252)=1.6, p=0.022)$. While the HF-Cheetos and HF-Froot groups differed from some other groups on Day 16 (Tukey's, $p$ 's $<0.05$ ), animals within each of the three diet manipulations did not consume different amounts of Cheetos ${ }^{\circledR}$ or Froot Loops ${ }^{\circledR}$, suggesting that they compensated for the different caloric content of the two USs.

CPP Testing (PD 61). Figure 3 shows the 95\% CIs for the mean difference scores for each group. Positive difference score values for the upper and lower bounds of the CI indicate a significant preference for the chamber paired with the US (Cheetos ${ }^{\circledR}$ or Froot Loops ${ }^{\circledR}$, accordingly), compared to the side paired with standard lab chow. The effect of the US food depended on the diet manipulation. The HF diet manipulation did not result in a preference for the side of the cage associated with either Cheetos ${ }^{\circledR}$ (HF-Cheetos) or Froot Loops ${ }^{\circledR}$ (HF-Froot Loops). In contrast, the HS diet manipulation resulted in a preference for the side of the cage associated with Cheetos $^{\circledR}$ (HS-Cheetos), the high fat US, but not a preference for the side associated with Froot Loops ${ }^{\circledR}$ (HSFroot Loops), the high sugar US. As expected, the Chow diet manipulation groups resulted in preferences for both Cheetos $^{\circledR}$ and for Froot Loops ${ }^{\circledR}$ (Chow-Cheetos and

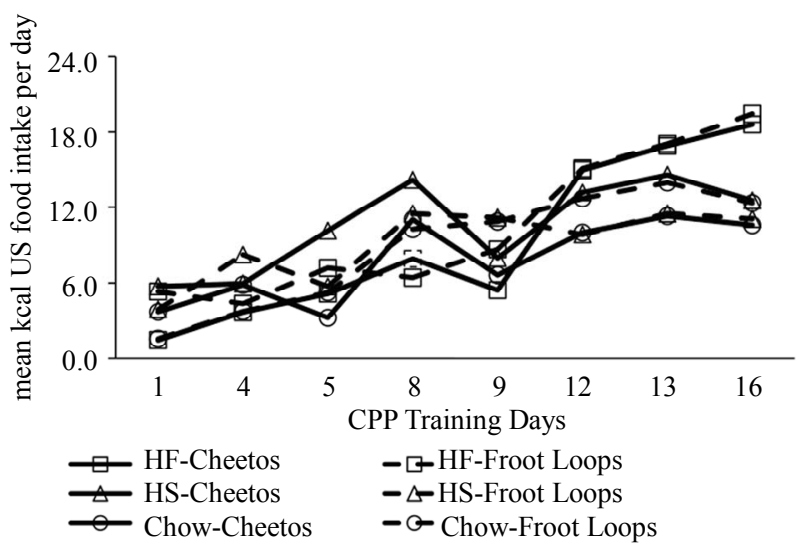

Figure 2. Mean intake of US food in kcal consumed during CPP training by rats with a history of pre- and periadolescent intake of HF, HS or lab chow diet.

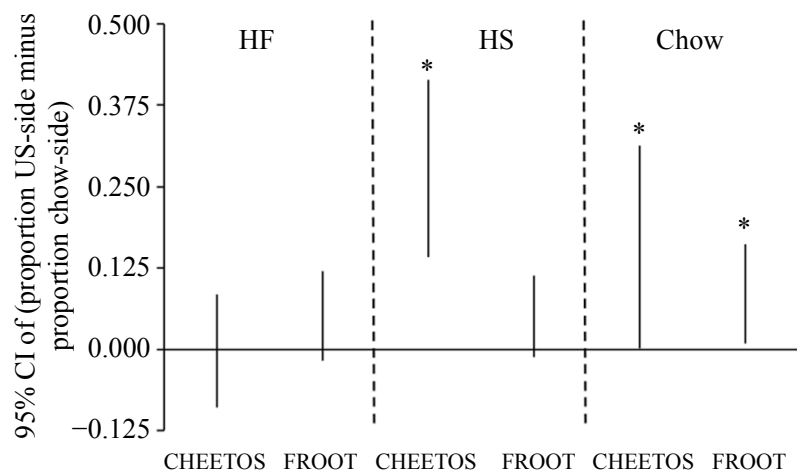

Figure 3. 95\% CIs for CPP preferences for the US food in CPP Test (Phase 4) for rats with a history of HF, HS, or lab chow diet during pre and periadolescence. An asterisk (*) indicates a $95 \%$ CI for intervals that did not envelop zero.

Chow-Froot Loops, respectively).

The number of chambers entrances in each side of the CPP chamber, summarized in Table 4, did not significantly differ overall $(F(1,30)=0.82, p=0.37)$, among groups $(F(5,30)=0.24, p=0.94)$, and did not differ based on which side was reinforced during training $(F(1$, $30)=0.003, p=0.96$ ).

Investigation during Objection Recognition Task. As with preference for a side of the CPP chamber, preference for the novel as compared to the familiar object was expressed as a difference score of the percentage of time 
investigating each object. This was done separately for the 1-hour and 24-hour follow-ups (Figure 4). For both follow-up tests, a $95 \%$ confidence interval above zero indicated a significant preference for the novel object. For the HF and HS groups, confidence intervals for both follow-up tests were above zero. For the Chow group, however, only the confidence interval for the 1-hour follow-up was above zero; the confidence interval for the 24-hour follow-up enveloped zero.

\section{Discussion}

In the present study, we tested the specificity hypothesis [9] to determine if HF diet intake in pre and periadolescence would lead to a general or specific deficit in CPP performance using a HF or HS US. In the present study, rats fed a HF diet in PD 21 - 40 had a general CPP deficit

Table 4. Mean and standard deviation for the number of chamber entrances in each side of the CPP apparatus during CPP testing on PD 61.

\begin{tabular}{ccccc}
\hline \multirow{2}{*}{ Group } & \multicolumn{2}{c}{ US-Paired Side } & \multicolumn{2}{c}{ Chow-Paired Side } \\
\cline { 2 - 5 } & Mean & SEM & Mean & SEM \\
\hline HF-C & 18.29 & 1.46 & 16.71 & 1.66 \\
HF-FL & 17.29 & 3.68 & 17.00 & 3.90 \\
HS-C & 16.57 & 1.82 & 16.14 & 1.68 \\
HS-FL & 18.00 & 1.95 & 19.14 & 1.72 \\
Chow-C & 20.29 & 2.04 & 20.14 & 2.03 \\
Chow-FL & 17.00 & 3.82 & 17.00 & 3.84 \\
\hline
\end{tabular}

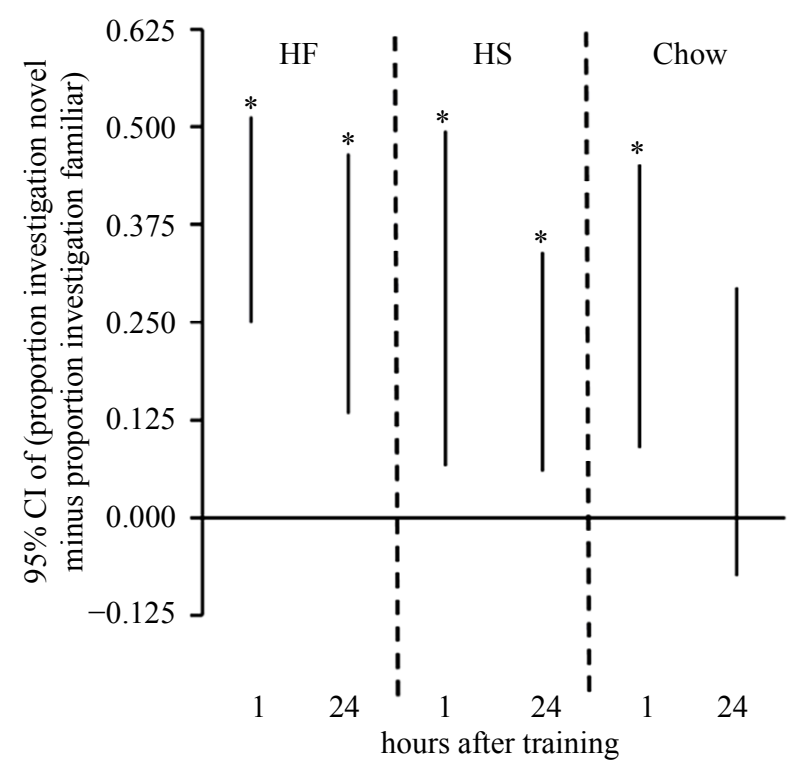

Figure 4. CIs for novelty preference during object recognition in 1-hour and 24-hour follow-up tests. An asterisk (*) indicates a $95 \%$ CI for intervals that did not envelop zero. in adulthood; in surprising contrast, rats fed a HS diet in PD 21 - 40 had a specific CPP deficit in adulthood; as expected, rats fed a lab chow diet in PD 21 - 40 showed no deficits in CPP performance in adulthood. Hence, the data shown here indicate that the specificity hypothesis can be rejected for subjects fed a HF diet in pre- and periadolescence, with CPP deficits observed when a HF and HS food was used as the US. Conversely, the specificity hypothesis was confirmed for subjects fed a HS diet in pre- and periadolescence, with CPP deficits observed when a HS, but not a HF food was used as the US.

Because HF diet intake in pre- and periadolescence can lead to neural impairments [8], we included a prioi, a follow-up test to determine the extensiveness of possible learning and memory deficits in the HF groups compared to the HS and Chow groups. In the present study, we included the NOR test, which (unlike CPP) is a nonassociative task $[23,24]$, and determined that all groups showed no deficits in STM and, if anything, the rats fed a HF and HS diet showed enhanced LTM. Hence, HF diet-induced CPP deficits do not reflect general learning and memory deficits, in that these same rats showed no deficits when a nonassociative task was given. Still, the general nature of the CPP deficits in the HF groups in an associative learning task is consistent with the suggestion that specific HF diet-induced neurogenesis impairments may cause these deficits, as has been suggested [8]. The extent to which this claim is true, and the localization of neural impairments specifically responsible for these deficits will require further research.

The specific CPP deficits in the HS groups can be more easily explained. A parsimonious explanation for the specific deficits in the HS groups is that HS intake in pre- and periadolescence devalues the motivational salience of a HS food used as a US in the CPP chamber [29], thereby leading to CPP deficits only when a HS food was used as a US. Hence, the HS food may not have been a sufficient US in that overexposure to a HS diet in preand periadolescence reduced the rewarding value of the HS food used in the CPP chamber. This explanation can fully account for why a CPP was only evident when a HF food was used as a US in the HS groups; but it is insufficient to explain the general CPP deficits observed in the HF groups, which we can speculate may likely be due to corresponding HF diet-induced neurogenesis impairments, as has been suggested [8]. At present, the biobehavioral data presented here do not lend further insights into the nature of the deficits observed.

Some alternative explanations for the pattern of results observed here can be eliminated. Body weights were the same between groups and are therefore not likely to explain these results. Motivational differences are also not likely to explain these findings inasmuch as intakes of the US foods in $\mathrm{g}$ and $\mathrm{kcal}$ in the HS and HF groups were 
at least as much as in the Chow groups. Still, rats could have expressed "liking" (i.e., it was palatable), but not "wanting" (i.e., sought it less) for the US foods [29,30]. However, rats in each group moved throughout the CPP apparatus in Phase 4 at comparable rates, which contradicts this possibility inasmuch as it would be expected that lower motivation to seek the US food would result in reduced locomotor activity in the CPP chamber. It is possible, nonetheless, that other factors such as unconditional locomotor activity elicited by the CPP chamber may have resulted in selective motivational effects of US exposure that cannot be completely ruled out.

\section{Conclusion}

Overall, the results presented here build upon previous literature by showing that pre- and periadolescent HFdiet induced CPP deficits are general (i.e., observed with a HF and a HS US), consistent with findings from Boitard et al. [8] showing that pre- and periadolescent intake of a HF-diet leads to substantial neurogenesis impairments that would be expected to lead to general deficits in associative learning. The fact that STM and LTM deficits were not observed in a NOR task suggests that the nature of the deficits does not apply to nonassociative learning and memory tasks. These results also provide a novel result that pre- and periadolescent HS diet-induced CPP deficits are nutrient-specific when a HS food (Froot Loops $^{\circledR}$ ) is used as a US, with CPP deficits possibly due to reduced sensory responsiveness to the HS US. Future studies will investigate the nature of the observed CPP deficits to determine if overlapping or separate mechanisms can best explain the different patterns of results observed here.

\section{Acknowledgements}

This research was partly supported by an internal sponsored faculty research grant awarded to the first author.

\section{REFERENCES}

[1] Kaiser Family Foundation, "Percent of Adults who Are Overweight or Obese," 2011.

http://kff.org/other/state-indicator/adult-overweightobesit y-rate/

[2] K. M. Flegal, D. F. Williamson, E. R. Pamuk and H. M. Rosenberg, "Estimating Deaths Attributable to Obesity in the United States," American Journal of Public Health, Vol. 94, No. 9, 2004, pp. 1486-1489. http://dx.doi.org/10.2105/AJPH.94.9.1486

[3] M. S. Faith, D. B. Allison and A. Geliebter, "Emotional Eating and Obesity: Theoretical Considerations and Practical Recommendations," In: S. Dalton, Ed., Overweight and Weight Management: The Health Professional's Guide to Understanding and Practice, Aspen Publishers, Gai- thersburg, 1997, pp. 439-465.

[4] F. Fernández-Armesto, "Near a Thousand Tables: A History of Food," Free Press, New York, 2002.

[5] R. Cserjésia, D. Molnár, O. Luminet and L. Lénárd, "Is There Any Relationship between Obesity and Mental Flexibility in Children?" Appetite, Vol. 49, 2007, pp. 675678. http://dx.doi.org/10.1016/j.appet.2007.04.001

[6] Y. Li, Q. Dai, J. C. Jackson and J. Zhang, "Overweight Is Associated with Decreased Cognitive Functioning among School-Age Children and Adolescents," Obesity, Vol. 16, 2008, pp. 1809-1815. http://dx.doi.org/10.1038/oby.2008.296

[7] L. G. Nilsson and E. Nilsson, "Overweight and Cognition," Scandinavian Journal of Psychology, Vol. 50, 2009, pp. 660-667. http://dx.doi.org/10.1111/j.1467-9450.2009.00777.x

[8] C. Boitard, N. Etchamendy, J. Sauvant, A. Aubert, S. Tronel, A. Marighetto, et al., "Juvenile, but Not Adult Exposure to High-Fat Diet Impairs Relational Memory and Hippocampal Neurogenesis in Mice," Hippocampus, Vol. 22, No. 11, 2012, pp. 2095-2100.

http://dx.doi.org/10.1002/hipo.22032

[9] G. J. Privitera, A. R. Zavala, F. Sanabria and K. L. Sotak, "High Fat Diet Intake during Pre and Periadolescence Impairs Learning of a Conditioned Place Preference in Adulthood," Behavioral and Brain Functions, Vol. 7, 2011, p. 21. http://dx.doi.org/10.1186/1744-9081-7-21

[10] M. Perello, I. Sakata, S. Birnbaum, J. C. Chuang, S. Osborne-Lawrence, S. A. Rovinsky, J. Woloszyn, et al., "Ghrelin Increases the Rewarding Value of High-Fat Diet in an Orexin-Dependent Manner," Biological Psychiatry, Vol. 67, 2010, pp. 880-886. http://dx.doi.org/10.1016/j.biopsych.2009.10.030

[11] M. Imaizumi, M. Takeda, A. Suzuki, S. Sawano and T. Fushiki, "Preference for High-Fat Food in Mice: Fried Potatoes Compared with Boiled Potatoes," Appetite, Vol. 36,2001 , pp. 237-238. http://dx.doi.org/10.1006/appe.2001.0399

[12] S. Matsumura, T. Yoneda, S. Aki, A. Eguchi, Y. Manabe, S. Tsuzuki, et al., "Intragastric Infusion of Glucose Enhances the Rewarding Effect of Sorbitol Fatty Acid Ester Ingestion as Measured by Conditioned Place Preference in Mice," Physiology \& Behavior, Vol. 99, 2010, pp. 509. 514. http://dx.doi.org/10.1016/j.physbeh.2009.12.018

[13] P. A. Jarosz, J. T. Kessler, P. Sekhon and D. V. Coscina, "Conditioned Place Preferences (CPPs) to High Caloric 'Snack Foods' in Rat Strains Genetically Prone vs. Resistant to Diet-Induced Obesity: Resistance to Naltrexone Blockade," Pharmacology, Biochemistry, and Behavior, Vol. 86, 2007, pp. 699-704.

[14] P. A. Jarosz, P. Sekhon and D. V. Coscina, "Effect of Opioid Antagonism on Conditioned Place Preferences to Snack Foods," Pharmacology, Biochemistry, and Behavior, Vol. 83, 2006, pp. 257-264. http://dx.doi.org/10.1016/j.pbb.2006.02.004

[15] M. T. Bardo, J. K. Rowlett and M. J. Harris, "Conditioned Place Preference Using Opiate and Stimulant Drugs: A Meta-Analysis," Neuroscience and Biobehavioral Re- 
views, Vol. 19, 1995, pp. 39-51. http://dx.doi.org/10.1016/0149-7634(94)00021-R

[16] T. M. Tzschentke, "Measuring Reward with the Conditioned Place Preference Paradigm: A Comprehensive Review of Drug Effects, Recent Progress and New Issues," Progress in Neurobiology, Vol. 56, 1998, pp. 613-672. http://dx.doi.org/10.1016/S0301-0082(98)00060-4

[17] L. P. Spear, "The Adolescent Brain and Age-Related Behavioral Manifestations," Neuroscience and Biobehavioral Reviews, Vol. 24, 2000, pp. 417-463. http://dx.doi.org/10.1016/S0149-7634(00)00014-2

[18] D. Dupret, A. Fabre, M. D. Dobrossy, A. Panatier, J. J. Rodriguez, S. Lamarque, et al., "Spatial Learning Depends on Both the Addition and Removal of New Hippocampus Neurons," PLOS Biology, Vol. 5, No. 8, 2007, pp. 1683-1694. http://dx.doi.org/10.1371/journal.pbio.0050214

[19] M. Koehl and D. N. Abrous, "A New Chapter in the Field of Memory: Adult Hippocampal Neurogenesis," European Journal of Neuroscience, Vol. 33, 2011, pp. 11011114. http://dx.doi.org/10.1111/j.1460-9568.2011.07609.x

[20] R. J. McDonald and N. M. White, "Information Acquired by the Hippocampus Interferes with Acquisition of the Amygdala-Based Conditioned Cue Preference (CCP) in the Rat," Hippocampus, Vol. 5, 1995, pp. 189-197. http://dx.doi.org/10.1002/hipo.450050305

[21] C. K. McIntyre, M. E. Ragozzino and P. E. Gold, "Intra-Amygdala Infusions of Scopolamine Impair Performance on a Conditioned Place Preference Task but Not a Spatial Radial Maze Task," Behavioural Brain Research, Vol. 2, 1998, pp. 219-226. http://dx.doi.org/10.1016/S0166-4328(97)00161-7

[22] T. Soon-Eng, "Roles of Hippocampal NMDA Receptors and Nucleus Accumbens D1 Receptors in the Amphetamine-Produced Conditioned Place Preference in Rats," Brain Research Bulletin, Vol. 77, 2008, pp. 412-419. http://dx.doi.org/10.1016/j.brainresbull.2008.09.007

[23] D. G. Mumby, "Perspectives on Object Recognition Memory Following Hippocampal Damage: Lessons from Stu- dies in Rats," Behavioural Brain Research, Vol. 127, 2001, pp. 159-181.

http://dx.doi.org/10.1016/S0166-4328(01)00367-9

[24] B. D. Winters, L. M. Saksida and T. J. Bussey, "Object Recognition Memory: Neurobiological Mechanisms of Encoding, Consolidation, and Retrieval," Neuroscience and Biobehavioral Reviews, Vol. 32, 2008, pp. 10551070 .

[25] N. M. Martins de Lima, J. Presti-Torres, A. Dornelles, E. Bromberg and N. Schröder, "Differential Effects of Low and High Doses of Trpiramate on Consolidation and Retrieval of Novel Object Recognition Memory in Rats," Epilepsy \& Behavior, Vol. 10, 2007, pp. 32-37. http://dx.doi.org/10.1016/j.yebeh.2006.09.007

[26] N. Schröder, S. J. O’Dell and J. F. Marshall, "Neurotoxic Methamphetamine Regimen Severely Impairs Recognition Memory in Rats," Synapse, Vol. 49, 2003, pp. 89-96. http://dx.doi.org/10.1002/syn.10210

[27] A. Bechara, F. Harrington, K. Nader and D. van der Kooy, "Neurobiology of Motivation: Double Dissociation of Two Motivational Mechanisms Mediating Opiate Reward in Drug-Naïve versus Drug Dependent Animals," Behavioral Neuroscience, Vol. 106, 1992, pp. 798-807. http://dx.doi.org/10.1037/0735-7044.106.5.798

[28] A. Bechara and D. van der Kooy, "A Single Brain Stem Substrate Mediates the Motivational Effects of Both Opiates and Food in Nondeprived Rats but Not in Deprived Rats," Behavioral Neuroscience, Vol. 106, 1992, pp. 351363. http://dx.doi.org/10.1037/0735-7044.106.2.351

[29] A. E. Kelley and K. C. Berridge, "The Neuroscience of Natural Rewards: Relevance to Addictive Drugs," The Journal of Neuroscience, Vol. 22, 2002, pp. 3306-3311.

[30] A. J. Tindell, K. S. Smith, K. C. Berridge and J. W. Aldridge, "Dynamic Computation of Incentive Salience: 'Wanting' What Was Never 'Liked,"' The Journal of Neuroscience, Vol. 29, 2009, pp. 12220-12228. http://dx.doi.org/10.1523/JNEUROSCI.2499-09.2009 